\title{
Effects of dietary marigold extract supplementation on growth performance, pigmentation, antioxidant capacity and meat quality in broiler chickens
}

\author{
Shuhao Wang', Lin Zhang ${ }^{1}$, Jiaolong $\mathrm{Li}^{1}$, Jiahui Cong ${ }^{1}$, Feng Gao ${ }^{1, *}$, and Guanghong Zhou'
}

\begin{abstract}
* Corresponding Author: Feng Gao Tel: +86-25-84399007, Fax: +86-25-84395314, Email: gaofeng0629@sina.com
\end{abstract}

'College of Animal Science and Technology, Key Laboratory of Animal Origin Food Production and Safety Guarantee of Jiangsu Province, Jiangsu Collaborative Innovation Center of Meat Production and Processing, Quality and Safety Control, Nanjing Agricultural University, Nanjing 210095, China

Submitted Jan 27, 2016; Revised Mar 27, 2016; Accepted Jun 1, 2016
Objective: This experiment was conducted to investigate the effects of dietary supplementation with marigold extract on growth performance, pigmentation, antioxidant capacity and meat quality in broiler chickens.

Methods: A total of 320 one-day-old Arbor Acres chickens were randomly divided into 5 groups with 8 replicates of 8 chickens each. The chickens of control group were fed with basal diet and other experimental groups were fed with basal diet supplemented with $0.075 \%, 0.15 \%$, $0.30 \%$, and $0.60 \%$ marigold extract respectively (the corresponding concentrations of lutein were $15,30,60$, and $120 \mathrm{mg} / \mathrm{kg}$ ).

Results: The results showed that marigold extract supplementation increased the yellowness values of shank, beak, skin and muscle and the redness $\left(\mathrm{a}^{*}\right)$ value of thigh muscle (linear, $\mathrm{p}<0.01$ ). Marigold extract supplementation significantly increased the total antioxidant capacity, and the activities of superoxide dismutase in liver and thigh muscle (linear, $\mathrm{p}<0.01$ ) and significantly decreased the malondialdehyde contents of liver and thigh muscle (linear, $\mathrm{p}<0.01$ ). Marigold extract supplementation significantly decreased the drip loss and shear force of thigh muscles (linear, $\mathrm{p}<0.01$ ). There was no significant effect on growth performance with marigold extract supplementation.

Conclusion: In conclusion, dietary supplementation of marigold extract significantly increased the yellowness values of carcass, antioxidant capacity and meat quality in broiler chickens.

Keywords: Marigold Extract, Lutein, Pigmentation, Antioxidant Capacity, Meat Quality, Broiler Chickens

\section{INTRODUCTION}

The color of skin and meat of chickens is an important factor in determining consumers' preference in many countries. Meat quality is often evaluated based on the color [1,2]. Neither the broiler itself can synthesize pigment [3], nor typical corn and soybean based commercial diets provide adequate quantity and types of pigments to meet consumers' preference for yellow chicken products [4]. In order to cater to the market demand, pigments are usually added into poultry feeds to enhance the yellowness of poultry products in commercial production, so, the color of poultry products is mainly the result of the pigment deposited into the tissues of poultry [5]. The pigments are divided into natural pigments and synthetic pigments depending on their origin. Most of the pigments used in the current poultry industry are synthetic pigments, which have been playing an important role in many countries for years. Although synthetic pigments are more stable in nature and lower in price than natural pigments, their safety has been questioned by some consumers [1]. Otherwise, the need for carotenoid-enriched products is now shaped [6] by the potential health promoting functions 
of natural pigments $[7,8]$. Therefore, people's interest in natural pigments is constantly increasing.

Marigold extract is a xanthophyll pigment mixture extracted from marigold flowers. Its active ingredient is lutein and a few zeaxanthins, a kind of carotenoid, which are deemed to be safe as they are naturally present in edible plants. Marigold meals and extracts are most widely accepted products in poultry feed among the natural pigments [4]. Previous studies had suggested that lutein can not only enhance skin color, but also has very strong antioxidant properties in several species $[1,3,9]$. And the antioxidant status is closely related to meat quality. However, most of the previous studies on dietary marigold extract in poultry have mainly concentrated upon the pigmentation of poultry and their products especially pigmentation of egg yolk. The purpose of this study was to evaluate the effect of dietary marigold extract on meat quality in broiler chickens and to explore the relationship between antioxidant capacity and meat quality.

\section{MATERIALS AND METHODS}

\section{Experiment materials and animals}

Experimental animals were healthy Arbor Acres (AA) male chickens purchased from Anhui Hewei Agricultural Development Co., Ltd. (Anhui, China). The marigold extract was obtained from Guangzhou Leader Biotechnology Co., Ltd. (Guangzhou, China). The extract used in this study was made from lutein ester which was extracted from marigold flowers by saponification and adsorption in carrier of defatted rice bran and silica. The effective content of lutein is $20 \mathrm{~g} / \mathrm{kg}$.

\section{Experimental design}

A total of 320 one-day-old AA chickens was randomly divided into 5 groups with 8 replicates (cages) of 8 chickens each. The chickens of control group were fed with basal diet and other test groups were fed with basal diet supplemented with $0.075 \%, 0.15 \%, 0.30 \%$, and $0.60 \%$ marigold extract respectively (the corresponding concentrations of lutein were 15, 30, 60, and $120 \mathrm{mg} / \mathrm{kg}$ ). The experiment was divided into starter phase ( 1 to $21 \mathrm{~d}$ ) and grower phase ( 22 to $42 \mathrm{~d}$ ). The composition and nutrient content of the basal diet is given in Table 1 .

\section{Management}

Chickens were housed in wire cages with $24 \mathrm{~h}$ lighting. Temperature and humidity were adjusted according to normal rearing conditions. All chickens were vaccinated by routine procedure and had free access to water and feed. Body weights of chickens and feed consumption were recorded per replicate on the morning of $1 \mathrm{~d}, 22 \mathrm{~d}$, and $42 \mathrm{~d}$. Then the growth performance expressed as feed intake (FI), body weight gain (BWG) and feed/gain (F/G) was calculated in starter phase (1 to $21 \mathrm{~d}$ ), grower phase (22 to $42 \mathrm{~d}$ ) and the whole period ( 1 to $42 \mathrm{~d}$ ). The experimental pro-
Table 1. The composition and nutrient content of the basal diet

\begin{tabular}{|c|c|c|}
\hline Items & Starter & Grower \\
\hline \multicolumn{3}{|l|}{ Ingredient (g/100 g) } \\
\hline Maize & 57.61 & 62.27 \\
\hline Soybean meal & 31.00 & 23.00 \\
\hline Maize gluten meal1) & 3.29 & 6.00 \\
\hline Soybean oil & 3.11 & 4.00 \\
\hline Dicalcium phosphate & 2.00 & 1.60 \\
\hline Limestone & 1.20 & 1.40 \\
\hline L-Lysine & 0.34 & 0.35 \\
\hline DL-Methionine & 0.15 & 0.08 \\
\hline Premix ${ }^{2)}$ & 1.00 & 1.00 \\
\hline Salt & 0.30 & 0.30 \\
\hline Total & 100.00 & 100.00 \\
\hline \multicolumn{3}{|l|}{ Nutrient levels $s^{3)}$} \\
\hline ME (MJ/kg) & 12.55 & 13.13 \\
\hline Crude protein (\%) & 21.10 & 19.57 \\
\hline Calcium (\%) & 1.00 & 0.95 \\
\hline Available phosphorus (\%) & 0.46 & 0.39 \\
\hline Lysine $(\%)$ & 1.20 & 1.05 \\
\hline Methionine (\%) & 0.50 & 0.42 \\
\hline \multicolumn{3}{|c|}{ 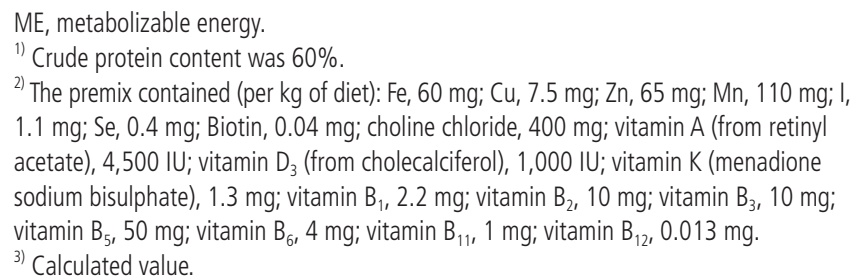 } \\
\hline
\end{tabular}

tocol was approved by the Institutional Animal Care and Use Committee of Nanjing Agricultural University.

\section{Sample collection}

One chicken with body weight near to average weight was selected from each cage on the morning of $42 \mathrm{~d}$. All of the 40 chickens were killed by exsanguination, and the $\mathrm{pH}$ of thigh muscle was measured by HI 9125 portable $\mathrm{pH}$ meter (Hanna Instruments Inc., Cluj-Napoca, Romania) after 45 min postmortem and then the muscle samples were packed into polyethylene bags for the subsequent determination of meat quality. Simultaneously, a few thigh muscle and liver tissue samples free of connective and fat tissues were cut into eppendorf tubes, stored at $-80^{\circ} \mathrm{C}$ for the determination of antioxidant capacity.

\section{Pigmentation}

Two chickens per replicate were selected randomly every seven days from 3 to 6 weeks and the yellow scores of shank and beak were evaluated using Kemin color fan (Kemin Industries [Asia] Pte Limited; color score from 3 to 14). On the morning of $42 \mathrm{~d}$, the yellowness $\left(b^{*}\right)$ value of skin was measured before slaughter by the Commission Internationale de L'Eclairage (CIE) lab system using a colorimeter (CR400, Konica Minolta Sensing, Inc., Osaka, Japan; calibrated with a white plate). According to the method of Castaneda et al [4], the measurements were 
taken in the lateral apterylum region which is free of any major blood vessels or feathers. The meat color ( $L^{*}$, lightness; $a^{*}$, redness; $b^{*}$, yellowness) of thigh muscle was also assessed from a cut surface by CR- 400 Chroma Meter at 24 h post-mortem, as described by Li et al [10]. Each muscle was measured 3 times at various points and the mean was calculated.

\section{Antioxidant capacity}

Firstly, thigh muscle and liver tissues were homogenized with a PRO 200 homogenizer (Pro Science Co., Ltd., Monroe, CT, USA) under low temperature conditions. Then, the homogenates were centrifuged to obtain supernatants and stored at $-20^{\circ} \mathrm{C}$ for subsequent analysis. The total antioxidant capacity (T-AOC), superoxide dismutase (SOD), glutathione peroxidase (GSH-PX) and malondialdehyde (MDA) contents were measured using the commercial assay kits produced by Nanjing Jiancheng Bioengineering Institute (Nanjing, China).

\section{Meat quality of thigh muscle}

The $\mathrm{pH}$ values of thigh muscles were measured at $45 \mathrm{~min}$ and $24 \mathrm{~h}$ after slaughter using HI 9125 portable $\mathrm{pH}$ meter (Hanna Instruments Inc., Romania) and expressed as $\mathrm{pH}_{45 \text { min }}$ and $\mathrm{pH}_{24} \mathrm{~h}$ respectively. The $\mathrm{pH}$ probe was inserted into the crevice made by surgical knife at a 45 -degree angle 3 times at various points on each sample and a mean value was calculated.

Drip loss of thigh muscles was measured in accordance with the method of Gao et al [11] with some modifications. About $30 \mathrm{~g}$ of muscle sample $(2 \mathrm{~cm} \times 3 \mathrm{~cm} \times 5 \mathrm{~cm})$ was cut from the same location of thigh muscle and then weighed $(\mathrm{m} 1)$. The samples were hung at $4^{\circ} \mathrm{C}$ in sealed aerated polyethylene bags ensuring that meat was not in contact with the bag and the direction of muscle fibers was perpendicular to ground. The surface moisture of samples was dried with filter paper and then the weight (m2) was measured again $24 \mathrm{~h}$ later. The following formula was used to calculate the drip loss: Drip loss rate $(\%)=(\mathrm{m} 1-\mathrm{m} 2) /$ $\mathrm{m} 1 \times 100$.
Shear force of thigh muscles was measured by C-LM3 digital meat tenderness meter (Engineering College of Northeast Agricultural University, Haerbin, China). Cooked meat was cut parallel to the direction of muscle fibers into 2 shaped strips $(1 \mathrm{~cm} \times 1 \mathrm{~cm} \times 3 \mathrm{~cm})$. Each strip was sheared two times perpendicular to direction of muscle fibers by tenderness meter and the force was expressed in Newtons (N). Each sample was measured 4 times at various points and the average value was calculated.

\section{Statistical analysis}

All data were analyzed by IBM SPSS Statistics 20 software and expressed as means and standard error of the mean (SEM). Comparisons of means were performed by Duncan's comparison test of one-way analysis of variance. The level of significance was evaluated at $p<0.05$. The effect of supplementation levels of marigold extract was determined using orthogonal polynomial contrast test for linear and quadratic effects.

\section{RESULTS}

\section{Growth performance}

Compared with the control, there was no significant difference in FI, BWG, and F/G of all test groups in all phases (Table 2).

\section{Pigmentation}

The yellow scores of shank and beak in all the groups increased gradually with the advancement of age from 3 week to 6 week (Figures 1 and 2). There was a high positive correlation between color scores of shank and additive amounts of marigold extract. The shank color scores of $0.60 \%$ and $0.30 \%$ supplementation groups had no significant differences at the last week. Beak color score was the largest in $0.60 \%$ marigold extract supplementation followed by $0.30 \%, 0.15 \%, 0.075 \%$, and the control.

No significant difference in $\mathrm{L}^{*}$ value of thigh muscles was observed between all four treatment groups and the control

Table 2. Effects of dietary marigold extract on the growth performance in broiler chickens

\begin{tabular}{|c|c|c|c|c|c|c|c|c|c|}
\hline \multirow{2}{*}{ Items } & \multicolumn{5}{|c|}{ The levels of marigold extract (\%) } & \multirow{2}{*}{ SEM } & \multirow{2}{*}{$p$ value } & \multicolumn{2}{|c|}{ Contrast } \\
\hline & 0 & 0.075 & 0.15 & 0.30 & 0.60 & & & Linear & Quadratic \\
\hline \multicolumn{10}{|l|}{0 to 3 week } \\
\hline BWG (g) & 579 & 563 & 573 & 539 & 547 & 8.3 & 0.534 & 0.151 & 0.978 \\
\hline$F / G$ & 1.58 & 1.59 & 1.61 & 1.61 & 1.62 & 0.010 & 0.750 & 0.188 & 0.947 \\
\hline \multicolumn{10}{|l|}{4 to 6 week } \\
\hline$F / G$ & 2.12 & 2.06 & 2.16 & 2.06 & 2.04 & 0.023 & 0.488 & 0.317 & 0.598 \\
\hline \multicolumn{10}{|l|}{0 to 6 week } \\
\hline $\mathrm{Fl}(\mathrm{g})$ & 4,072 & 3,901 & 4,032 & 4,086 & 3,891 & 38.6 & 0.328 & 0.516 & 0.697 \\
\hline BWG (g) & 2,070 & 2,027 & 2,018 & 2,104 & 2,028 & 22.4 & 0.732 & 0.972 & 0.886 \\
\hline $\mathrm{F} / \mathrm{G}$ & 1.97 & 1.93 & 2.00 & 1.94 & 1.93 & 0.016 & 0.613 & 0.516 & 0.577 \\
\hline
\end{tabular}

SEM, standard error of the means; $F$, feed intake; BWG, body weight gain; F/G, FI/BWG; $n=8$. 


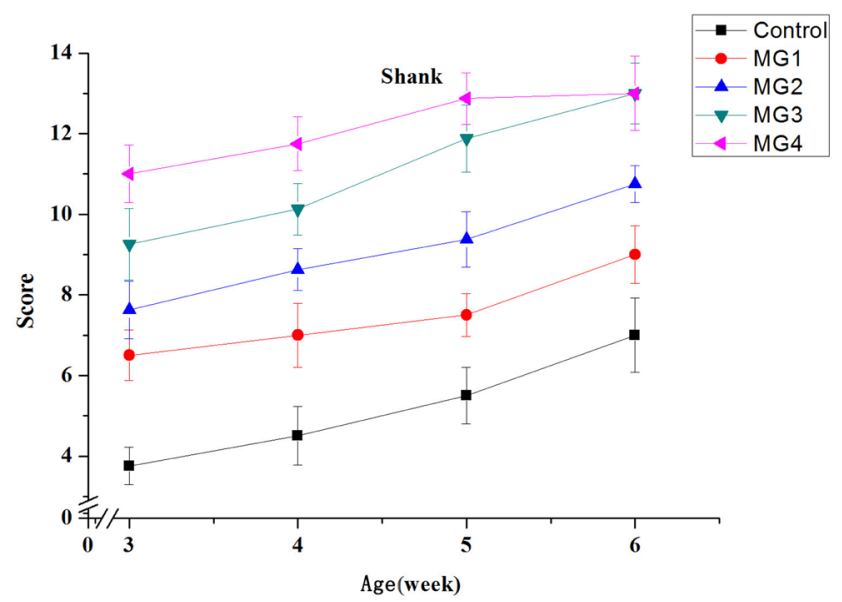

Figure 1. Effects of dietary marigold extract on yellow score of shank in broiler chickens. MG1, 0.075\% marigold extract; MG2, 0.15\% marigold extract; MG3, $0.30 \%$ marigold extract; MG4, $0.60 \%$ marigold extract; 3 , the lowest yellow score; 14 , the highest yellow score. $n=8$.

(Table 3). Compared with the control, marigold extract supplementation increased $\mathrm{a}^{*}$ value of thigh muscle, especially in the $0.60 \%$ group (linear, $p<0.01$ ). Furthermore, marigold extract significantly increased $b^{*}$ value of thigh muscle and skin compared with the control (linear, $\mathrm{p}<0.01$ ), except for the $0.075 \%$ group. The response of $a^{*}$ value of thigh muscle and $b^{*}$ value of thigh muscle and skin to supplemental marigold extract all

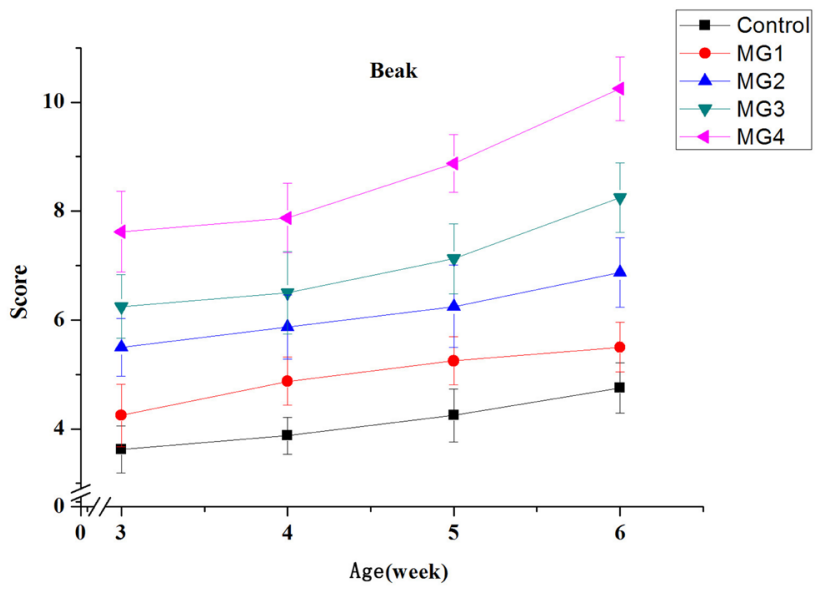

Figure 2. Effects of dietary marigold extract on yellow score of beak in broiler chickens. MG1, $0.075 \%$ marigold extract; MG2, 0.15\% marigold extract; MG3, $0.30 \%$ marigold extract; MG4, $0.60 \%$ marigold extract; 3 , the lowest yellow score; 14 , the highest yellow score. $n=8$.

were linear $(\mathrm{p}<0.01)$, and the $\mathrm{a}^{*}$ value and $\mathrm{b}^{*}$ value were maximized by adding $0.60 \%$ marigold extract.

\section{Antioxidant capacity}

In comparison to the control group, supplementation with marigold extract significantly linearly increased T-AOC and activities of GSH-PX of liver in all four treatment groups (Table 4)

Table 3. Effects of dietary marigold extract on the color of thigh muscle and skin in broiler chickens

\begin{tabular}{|c|c|c|c|c|c|c|c|c|c|}
\hline \multirow{2}{*}{ Items } & \multicolumn{5}{|c|}{ The levels of marigold extract (\%) } & \multirow{2}{*}{ SEM } & \multirow{2}{*}{$p$ value } & \multicolumn{2}{|c|}{ Contrast } \\
\hline & 0 & 0.075 & 0.15 & 0.30 & 0.60 & & & Linear & Quadratic \\
\hline Muscle $L^{*}$ & 41.72 & 41.50 & 41.75 & 43.78 & 43.65 & 0.420 & 0.213 & 0.041 & 0.566 \\
\hline Muscle $a^{*}$ & $3.62^{b}$ & $4.06^{\mathrm{ab}}$ & $4.29^{\mathrm{ab}}$ & $4.20^{\mathrm{ab}}$ & $5.47^{\mathrm{a}}$ & 0.197 & 0.035 & 0.005 & 0.380 \\
\hline Muscle $b^{*}$ & $5.47^{d}$ & $6.14^{\mathrm{cd}}$ & $7.52^{c}$ & $9.88^{b}$ & $13.02^{\mathrm{a}}$ & 0.510 & $<0.001$ & $<0.001$ & 0.012 \\
\hline Skin b* & $10.23^{c}$ & $11.39^{\mathrm{bc}}$ & $12.63^{\mathrm{ab}}$ & $13.26^{\mathrm{ab}}$ & $14.38^{\mathrm{a}}$ & 0.377 & 0.002 & $<0.001$ & 0.797 \\
\hline
\end{tabular}

SEM, standard error of the means; $L^{*}$, lightness; $a^{*}$, redness; $b^{*}$, yellowness.

$a, b, c, d$ Means within the same row with no common superscript differ significantly $(p<0.05) . n=8$.

Table 4. Effects of dietary marigold extract on the antioxidant capacity of liver and thigh muscle in broiler chickens

\begin{tabular}{|c|c|c|c|c|c|c|c|c|c|}
\hline \multirow{2}{*}{ Items } & \multicolumn{5}{|c|}{ The level of marigold extract (\%) } & \multirow{2}{*}{ SEM } & \multirow{2}{*}{$p$ value } & \multicolumn{2}{|c|}{ Contrast } \\
\hline & 0 & 0.075 & 0.15 & 0.30 & 0.60 & & & Linear & Quadratic \\
\hline \multicolumn{10}{|l|}{ Liver } \\
\hline SOD (U/mg of protein) & $289.7^{c}$ & $329.9^{b c}$ & $337.5^{b}$ & $337.5^{b}$ & $398.3^{\mathrm{a}}$ & 8.37 & $<0.001$ & $<0.001$ & 0.547 \\
\hline GSH-PX (U/mg of protein) & $43.4^{c}$ & $48.6^{b}$ & $49.2^{b}$ & $52.7^{\mathrm{ab}}$ & $57.6^{\mathrm{a}}$ & 1.07 & $<0.001$ & $<0.001$ & 0.731 \\
\hline MDA (nmol/mg of protein) & $1.8^{\mathrm{a}}$ & $1.8^{\mathrm{a}}$ & $1.6^{\mathrm{a}}$ & $1.6^{\mathrm{a}}$ & $1.2^{b}$ & 0.07 & 0.011 & 0.001 & 0.172 \\
\hline SOD (U/mg of protein) & $20.3^{c}$ & $25.8^{\mathrm{b}}$ & $25.4^{b}$ & $27.5^{b}$ & $35.9^{\mathrm{a}}$ & 1.07 & $<0.001$ & $<0.001$ & 0.190 \\
\hline GSH-PX (U/mg of protein) & 8.1 & 8.5 & 9.6 & 9.6 & 11.2 & 0.55 & 0.441 & 0.070 & 0.773 \\
\hline MDA (nmol/mg of protein) & $1.2^{\mathrm{a}}$ & $0.8^{b}$ & $0.9^{b}$ & $0.7^{b}$ & $0.7^{b}$ & 0.04 & $<0.001$ & $<0.001$ & 0.021 \\
\hline
\end{tabular}

SEM, standard error of the means; T-AOC, total antioxidant capacity; SOD, superoxide dismutase; GSH-PX, glutathione peroxidase; MDA, malondialdehyde.

a,b,c Means within the same row with no common superscript differ significantly $(p<0.05) . n=8$. 
$(\mathrm{p}<0.01)$. Meanwhile, the SOD activity significantly increased in all other treatment groups (linear, $\mathrm{p}<0.01$ ), except for $0.075 \%$ group. Dietary marigold extract decreased the concentrations of MDA, especially in $0.60 \%$ group (linear, $\mathrm{p}<0.01$ ).

In comparison to the control, supplementation with marigold extract increased T-AOC in thigh muscle, especially in $0.30 \%$, $0.60 \%$ groups (linear, $\mathrm{p}<0.01$ ), and significantly increased activities of SOD in all four treatment groups (Table 4 ) (linear, $\mathrm{p}<0.01$ ). There were no significant differences in activities of GSH-PX. The concentrations of MDA significantly decreased in all the treatment groups (linear, $\mathrm{p}<0.01$ ).

\section{Meat quality}

Addition of marigold extract had no significant effect on $\mathrm{pH}_{45 \text { min }}$ or on $\mathrm{pH}_{24 \mathrm{~h}}$ in the thigh muscle (Table 5). Compared with the control group, marigold extract supplementation significantly decreased $(\mathrm{p}<0.01)$ linearly the drip loss of thigh muscle in all the treatment groups. On the other hand, supplementation with marigold extract significantly decreased the shear force of thigh muscle in all the test groups (linear, $\mathrm{p}<0.01$ ) except for $0.075 \%$ group.

\section{DISCUSSION}

\section{Pigmentation}

In terms of food, color, classified in freshness, is one of the crucial criteria determining consumers' choice [12]. In addition, meat color, which is the external manifestation of a variety of physiological and biochemical changes in muscle, is the most intuitive index of meat quality. Moreover, shank and beak are typically used to evaluate pigmentation of chickens in production. The results of this experiment showed that the addition of marigold extract significantly increased the yellow scores of shank and beak. This implies that the experimental groups deposited more yellow xanthophyll pigments such as lutein. For shank, the addition of $0.30 \%$ showed the same result as $0.60 \%$ group in the end, which means the yellowness of shank can reach the maximum when the marigold extract content was at $0.30 \%$. This also indicates that different tissues have different deposition efficiency of marigold extract pigments. In the present study, we also found that the addition of marigold extract significantly increased the $b^{*}$ value of the thigh muscle and skin. This might be due to deposition of marigold extract pigments in the muscle and skin, and many previous studies have obtained similar results [13-15]. Castaneda et al [4] also indicated that natural pigments were generally more effective than synthetic ones in improving the yellowness of animal skin. The marigold extract increased the $\mathrm{a}^{*}$ value of thigh muscle in this study. Vitamin $\mathrm{E}$ could directly prevent lipid oxidation and then delay myoglobin oxidation [16]. The increase of lipid peroxidation products will accelerate the oxidation of bright red oxygenated myoglobin to brown metmyoglobin, and then the color of meat will become dark brown [17]. Furthermore, lutein has stronger antioxidant capacity than vitamin E [18]. So, the increased $\mathrm{a}^{*}$ value might be due to the decreased muscle peroxidation. On the other hand, Rajput et al [19] concluded that the increase of $a^{*}$ value may be linked to higher levels of hemoglobin in the tissue.

\section{Antioxidant capacity}

Antioxidant capacity is an important factor affecting the health of the animal, and the antioxidant capacity of muscle after slaughter is one of the most critical factors affecting meat quality. Lipid peroxidation caused by high levels of free radicals not only can induce oxidative stress and increase the content of MDA which is the end product of lipid oxidation [20], but also causes the deterioration of meat. In addition, the oxidation of lipid is closely related to meat color and the accumulation of antioxidant substances can increase the color stability of meat [21]. So, improving the antioxidant properties of muscle is of great significance to improve meat quality and increase meat storage time. Studies have indicated that the addition of antioxidants in the diet can alleviate the adverse effects of oxidative stress on broiler production and improve the meat quality of broilers [22]. T-AOC is a reflection of the body or tissue antioxidant properties. $\mathrm{SOD}$ can remove superoxide anion free radicals and GSH-PX can catalyze the decomposition of hydrogen peroxide.

The groups with dietary marigold extract supplementation had higher antioxidant capacity of livers and thigh muscles in all four antioxidant indices, which were consistent with the findings of Shanmugasundaram and Selvaraj [23] and Rajput et al [19]. Lutein and zeaxanthin have a number of unsaturated bonds, so they can quench reactive oxygen species (ROS) [24], thereby inhibiting the activity of oxygen free radicals and preventing reactive oxygen free radicals from destroying normal

Table 5. Effects of dietary marigold extract on the meat quality of thigh muscle in broiler chickens

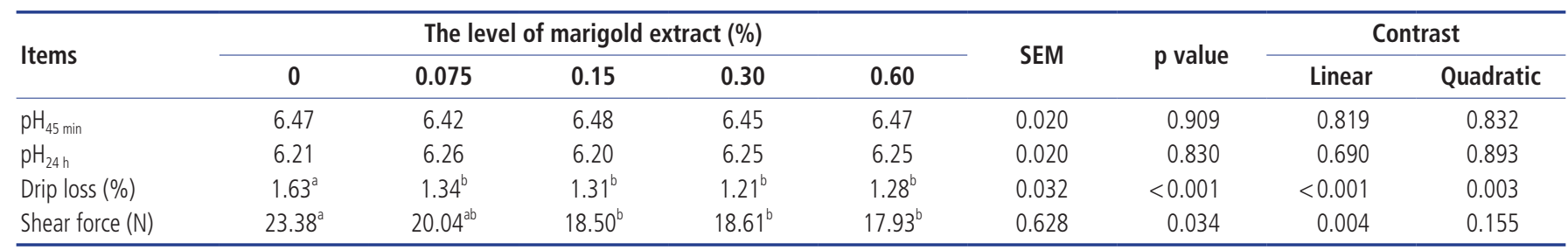

SEM, standard error of the means.

${ }_{a, b}$ Means within the same row with no common superscript differ significantly $(p<0.05) . n=8$. 
cells. Chew and Park [25] also reported that lutein has a unique effect in preventing damage of the biofilm from free radical quenching singlet oxygen and free radical capture. Natural carotenoids can mitigate lipid oxidation of breast muscle [19]. Dietary supplementation of lutein prevented an increase of LPS-induced thiobarbituric acid reactive substances [23]. This is consistent with the decreased MDA observed in the current trial. Thus, lutein with the capacity of reducing oxidative stress in birds is an excellent antioxidant [26].

\section{Meat quality}

Meat quality is usually measured by $\mathrm{pH}$, meat color, water holding capacity and tenderness. Water holding capacity refers to the ability of muscle tissue to maintain moisture and directly affects the eating quality of meat, such as taste, tenderness, nutrition level and so on [27]. Consumers consider tenderness as one of the most important eating qualities of meat. Muscle tenderness is affected by many factors with the content and chemical structure state of connective tissue and the myofibrils and sarcoplasmic reticulum being the material basis of tenderness. This study suggested that supplementation of marigold extract reduced drip loss as well as shear force, improved the water holding capacity and the tenderness of thigh muscle. No significant effect was observed on pH. Rajput et al [19] also found that natural carotenoid improved the meat's water holding capacity of broilers affected by a coccidiosis challenge. The enhancement of water holding capacity might have been caused by the improvement of antioxidant in muscle. Study has also indicated that carotenoids are regarded to improve muscle water holding capacity [19]. Proteolysis and even protein oxidation directly affects the water holding capacity in muscle tissue [28]. Otherwise, the calpain activity which plays an important role in water holding capacity can be modulated by redox state [29]. The improvement of tenderness also might have been caused by the increase in antioxidant ability, or affected by water holding capacity of muscle, which can directly affect the tenderness of meat [27]. Rowe et al [30] had reported that muscle oxidation can reversibly inhibit the activities of muscle protein degradation enzymes and other protein hydrolases after postmortem, and then reduce muscle tenderness.

Meat quality is related to oxidant property and the enhancement of its antioxidant property ameliorates meat quality through different ways [31]. The rate and degree of lipid oxidation in postmortem muscle depends on the antioxidant capacity of the body, while SOD can block lipid oxidation, improve the meat quality and prolong the shelf life of meat. Besides, it has been reported that ROS could reduce collagen synthesis and increase matrix metalloproteinase-2, which has a negative effect on meat quality, and ROS could be eliminated by lutein [32]. The decline of MDA content in muscle is an indirect effect of the antioxidant capacity, which might be another reason [31].

\section{CONCLUSION}

In conclusion, marigold extract supplementation can not only enhance the yellowness values of shank, beak, skin and muscle, but also increase the antioxidant capacity of body, improve antioxidant capacity and meat quality. No adverse effects of high added amount of marigold extract were found in the current experiment. We can choose the appropriate supplementation dosage of marigold extract according to the specific consumer preferences and consideration of the production cost.

\section{CONFLICT OF INTEREST}

We certify that there is no conflict of interest with any financial organization regarding the material discussed in the manuscript.

\section{ACKNOWLEDGMENTS}

This study was supported by the National Science \& Technology Pillar Program during the Twelfth Five-year Plan Period of China (2012BAD28B03).

\section{REFERENCES}

1. Liu G-D, Hou G-Y, Wang D-J, et al. Skin pigmentation evaluation in broilers fed different levels of natural okra and synthetic pigments. J Appl Poult Res 2008;17:498-504.

2. Velasco V, Williams P. Improving meat quality through natural antioxidants. Chil J Agr Res 2011;71:313-22.

3. Lokaewmanee K, Yamauchi K, Komori T, Saito K. Enhancement of yolk color in raw and boiled egg yolk with lutein from marigold flower meal and marigold flower extract. J Poult Sci 2011;48:2532.

4. Castaneda M, Hirschler E, Sams A. Skin pigmentation evaluation in broilers fed natural and synthetic pigments. Poult Sci 2005;84: 143-7.

5. Perez-Vendrell A, Hernandez J, Llaurado L, Schierle J, Brufau J. Influence of source and ratio of xanthophyll pigments on broiler chicken pigmentation and performance. Poult Sci 2001;80:320-6.

6. Karadas F, Grammenidis E, Surai P, Acamovic T, Sparks N. Effects of carotenoids from lucerne, marigold and tomato on egg yolk pigmentation and carotenoid composition. Br Poult Sci 2006;47: 561-6.

7. Moeller SM, Jacques PF, Blumberg JB. The potential role of dietary xanthophylls in cataract and age-related macular degeneration. J Am Coll Nutr 2000;19:522S-7S.

8. Johnson EJ. The role of carotenoids in human health. Nutr Clin Care 2002;5:56-65.

9. Alves-Rodrigues A, Shao A. The science behind lutein. Toxicol Lett 2004;150:57-83.

10. Li Y, Li J, Zhang L, et al. Effects of dietary energy sources on post mortem glycolysis, meat quality and muscle fibre type transfor- 
mation of finishing pigs. PloS One 2015;10:e0131958.

11. Gao T, Li J, Zhang L, et al. Effect of different tumbling marination treatments on the quality characteristics of prepared pork chops. Asian-Australas J Anim Sci 2015;28:260-7.

12. Baker R, Günther C. The role of carotenoids in consumer choice and the likely benefits from their inclusion into products for human consumption. Trends Food Sci Technol 2004;15:484-8.

13. Ponsano EHG, Pinto M, Garcia-Neto M, Lacava P. Performance and color of broilers fed diets containing Rhodocyclus gelatinosus biomass. Rev. Bras Cienc Avic 2004;6:237-42.

14. Sirri F, Petracci M, Bianchi M, Meluzzi A. Survey of skin pigmentation of yellow-skinned broiler chickens. Poult Sci 2010;89:155661.

15. Rajput N, Naeem M, Ali S, et al. The effect of dietary supplementation with the natural carotenoids curcumin and lutein on broiler pigmentation and immunity. Poult Sci 2013;92:1177-85.

16. Morrissey PA, Buckley DJ, Sheehy P, Monahan F. Vitamin E and meat quality. Proc Nutr Soc 1994;53:289-95.

17. Satoh Y, Shikama K. Autoxidation of oxymyoglobin. A nucleophilic displacement mechanism. J Biol Chem 1981;256:10272-5.

18. Reddy ACP, Lokesh B. Studies on spice principles as antioxidants in the inhibition of lipid peroxidation of rat liver microsomes. Mol Cell Biochem 1992;111:117-24.

19. Rajput N, Ali S, Naeem M, Khan M, Wang T. The effect of dietary supplementation with the natural carotenoids curcumin and lutein on pigmentation, oxidative stability and quality of meat from broiler chickens affected by a coccidiosis challenge. Br Poult Sci 2014;55: 501-9.

20. Kim JE, Clark RM, Park Y, Lee J, Fernandez ML. Lutein decreases oxidative stress and inflammation in liver and eyes of guinea pigs fed a hypercholesterolemic diet. Nutr Res Pract 2012;6:113-9.

21. Faustman C, Cassens R. The biochemical basis for discoloration in fresh meat: a review. J Muscle Foods 1990;1:217-43.

22. Gao J, Lin H, Wang X, Song Z, Jiao H. Vitamin E supplementation alleviates the oxidative stress induced by dexamethasone treatment and improves meat quality in broiler chickens. Poult Sci 2010;89: 318-27.

23. Shanmugasundaram R, Selvaraj R. Lutein supplementation alters inflammatory cytokine production and antioxidant status in F-line turkeys. Poult Sci 2011;90:971-6.

24. Trevithick-Sutton CC, Foote CS, Collins M, Trevithick JR. The retinal carotenoids zeaxanthin and lutein scavenge superoxide and hydroxyl radicals: a chemiluminescence and ESR study. Mol Vis 2006;12:1127-35.

25. Chew BP, Park JS. Carotenoid action on the immune response. J Nutr 2004;134:257S-61S.

26. Hõrak P, Sild E, Soomets U, Sepp T, Kilk K. Oxidative stress and information content of black and yellow plumage coloration: an experiment with greenfinches. J Exp Biol 2010;213:2225-33.

27. Judge M, Reeves E, Aberle E. Effect of electrical stimulation on thermal shrinkage temperature of bovine muscle collagen. J Anim Sci 1981;52:530-4.

28. Huff-Lonergan E, Lonergan SM. Mechanisms of water-holding capacity of meat: The role of postmortem biochemical and structural changes. Meat Sci 2005;71:194-204.

29. Guttmann RP, Johnson GV. Oxidative stress inhibits calpain activity in situ. J Biol Chem 1998;273:13331-8.

30. Rowe LJ, Maddock K, Lonergan SM, Huff-Lonergan E. Oxidative environments decrease tenderization of beef steaks through inactivation of $\mu$-calpain. J Anim Sci 2004;82:3254-66.

31. Guo Z, Li J, Zhang L, et al. Effects of alpha-lipoic acid supplementation in different stages on growth performance, antioxidant capacity and meat quality in broiler chickens. Br Poult Sci 2014; 55:635-43.

32. Archile-Contreras A, Purslow P. Oxidative stress may affect meat quality by interfering with collagen turnover by muscle fibroblasts. Food Res Int 2011;44:582-8. 